\title{
Avaliação imediata da troponina I cardíaca em pacientes submetidos à revascularização do miocárdio
}

\author{
João Carlos F. LEAL*,**, Domingo M. BRAILE*,**, Moacir F. GODOY*,**, José PURINI NETO**, \\ Alfredo de PAULA NETO** , Serginando L. RAMIN****, Marcos ZAIANTCHICK*,**
}

RBCCV 44205-466

\begin{abstract}
Leal J C F, Braile D M, Godoy M F, Purini Neto J, Paula Neto A, Ramin S L, Zaiantchick M - Avaliação imediata da troponina I cardíaca em pacientes submetidos à revascularização do miocárdio. Rev Bras Cir Cardiovasc 1999; 14 (3): 247-53.
\end{abstract}

RESUMO: O presente trabalho foi desenvolvido com o objetivo de determinar o comportamento evolutivo imediato e o valor prognóstico em termos de sobrevivência tardia, da dosagem sérica de troponina I em pacientes submetidos a operações cardíacas para revascularização miocárdica. Foram analisados 108 pacientes, não selecionados, sendo $85(78,7 \%)$ do sexo masculino, submetidos à operação de revascularização do miocárdio com ou sem auxílio de circulação extracorpórea, no período de dezembro de 1996 a dezembro de 1997. O método empregado na dosagem da troponina I foi o da Quimioluminiscência, em equipamento Acess da Sanofi-Pasteur. Foram feitas dosagens no pré-operatório, logo na chegada na Unidade de Terapia Intensiva, no primeiro e no segundo dia de pós-operatório, adquirindo-se como normais valores abaixo de 0,1 nanogramas por mililitro $(\mathrm{ng} / \mathrm{ml})$. Foram estabelecidos níveis de corte para avaliação prognóstica. Os pacientes foram avaliados pós-operatoriamente, registrando-se a evolução em meses, com vistas à determinação das taxas de sobrevivência. A dosagem de troponina lem pacientes submetidos a operações de revascularização miocárdica mostrou comportamento evolutivo agudo característico, com importante elevação dos níveis séricos no primeiro dia de pós-operatório. Pacientes operados com auxílio de circulação extracorpórea (CEC) mostraram níveis significativamente mais elevados, mas não houve correlação com tempo de isquemia ou tempo de CEC, sugerindo que a elevação da troponina I seja decorrente de sofrimento miocárdico específico (obstrução coronária, oclusão de ponte, etc.) e não decorrente da CEC propriamente dita. Foi ainda possível determinar que os níveis de corte estabelecidos separam pacientes com mau prognóstico, uma vez que valores acima de $2,5 \mathrm{ng} / \mathrm{ml}$ no primeiro dia de pós-operatório levaram a taxas de mortalidade de $33 \%$ a $50 \%$ em tempo máximo de seis meses de seguimento. A troponina l eleva-se em pacientes submetidos a operações de revascularização miocárdica, traduzindo sofrimento celular mesmo nos casos sem emprego de circulação extracorpórea. Valores de troponina I em torno de $2,5 \mathrm{ng} / \mathrm{ml}$ no primeiro dia de pós-operatório devem alertar para a necessidade de medidas diagnósticas ou terapêuticas mais agressivas.

DESCRITORES: Revascularização miocárdica, mortalidade. Troponina I, sangue.

Trabalho realizado na Faculdade de Medicina de São José do Rio Preto e no Hospital Infante D. Henrique da Sociedade Portuguesa de Beneficência. São José do Rio Preto, SP, Brasil.

Apresentado ao $26^{\circ}$ Congresso Nacional de Cirurgia Cardíaca. Fortaleza, CE, 8 a 10 de abril de 1999

* Da Faculdade de Medicina de São José do Rio Preto.

** Do Hospital Infante D. Henrique da Sociedade Portuguesa de Beneficência.

Endereço para correspondência: João Carlos F. Leal. Av. Juscelino Kubitschek 3101. São José do Rio Preto, SP, Brasil - CEP: 15091-450 - Tel.: (017) 227-4988.e-mail: joaocarlos@braile.com.br 
Leal J C F, Braile D M, Godoy M F, Purini Neto J, Paula Neto A, Ramin S L, Zaiantchick M - Avaliação imediata da troponina I cardíaca em pacientes submetidos à revascularização do miocárdio. Rev Bras Cir Cardiovasc 1999; 14 (3): 247-53.

\section{INTRODUÇÃO}

A isquemia miocárdica grave, que ocorre nos casos de infarto agudo do miocárdio ou em alguns pacientes com angina instável, resulta em injúria seguida pela liberação de constituintes celulares, taxas da isoforma miocárdica da creatinoquinase (CK-MB) e da desidrogenase láctica (DHL), na corrente sangüínea. Existem, porém, limitações, uma vez que a especificidade fica comprometida nos casos de acometimento muscular esquelético associado e, além disso, a sensibilidade é baixa nas primeiras horas de evolução, devido ao aparecimento retardado desses marcadores no sangue. Acrescente-se que a sensibilidade da CK-MB não é suficientemente alta para detectar dano miocárdico leve, face à imprecisão analítica das medidas de atividade e à ampla faixa de normalidade ${ }^{(1)}$.

Recentemente, as troponinas têm recebido crescente atenção como marcadores altamente específicos de injúria celular miocárdica ${ }^{(2,3)}$. Em pacientes com infarto agudo do miocárdio, a elevação da atividade da creatino-fosfoquinase acima dos valores normais é raramente encontrada antes de 4 a $6 \mathrm{~h}$ após o início da dor, fazendo que o diagnóstico precoce tenha que depender fortemente de alterações eletrocardiográficas típicas. Isso torna-se um problema pelo fato de que o eletrocardiograma é inconclusivo em até $40 \%$ dos pacientes. Ao contrário da CK-MB, a troponina I cardíaca (Tnl-c) é altamente específica para o tecido miocárdico, não é detectável no sangue de pessoas sadias, mostra um aumento proporcionalmente bem maior acima dos valores limite nos casos de infarto do miocárdio e pode permanecer elevada por 7 a 10 dias após o episódio agudo ${ }^{(4,5)}$. MAIR et al. ${ }^{(6)}$ demonstraram que o primeiro sinal de elevação das concentrações de troponina em pacientes com infarto do miocárdio ocorria já com 3,5 h de evolução em $50 \%$ dos casos, sendo necessárias $4,75 \mathrm{~h}$, em média, para se obter a mesma taxa de comprometimento com a CK-MB. Com $7 \mathrm{~h}$ de evolução, 95\% dos pacientes apresentavam alteração da troponina, fato só igualado com a CK-MB após $12 \mathrm{~h}$ de início dos sintomas.

A cirurgia cardíaca exige, na grande maioria das vezes, que o coração permaneça estático e exangue enquanto se realiza o procedimento. Para tanto, são utilizados os circuitos de circulação extracorpórea que dão o suporte cardíaco e pulmonar durante o tempo operatório. Já está bem documentado que, durante esse tempo de parada, o coração sofre um processo de isquemia controlada que culmina em maior ou menor quantidade de morte tecidual (infarto). O diagnóstico de infarto peri-operatório muitas vezes é difícil tanto pela sedação do paciente e intubação, impedindo a comunicação verbal de sintomas, como pela baixa sensibilidade e especificidade fornecida pelos monitores eletrocardiográficos comuns, restritos na maioria das vezes a apenas uma ou no máximo duas derivações. MAIR et al. (7) utilizaram a troponina I para avaliar a ocorrência de infarto miocárdico peri-operatório em pacientes submetidos à revascularização miocárdica com pontes de safena.

O objetivo do presente estudo é determinar o comportamento evolutivo imediato e o valor prognóstico em termo de sobrevivência (17 meses) da dosagem sérica de troponina I, em pacientes submetidos a operações cardíacas para revascularização do miocárdio.

\section{CASUÍSTICA E MÉTODOS}

Foram estudados 108 pacientes, não selecionados, sendo $85(78,7 \%)$ do sexo masculino, submetidos à operação de revascularização do miocárdio com ou sem auxílio de circulação extracorpórea, no período de dezembro de 1996 a dezembro de 1997. Nos 88 $(81,5 \%)$ pacientes submetidos à circulação extracorpórea, foi empregada a técnica de cardioplegia sangüínea anterógrada/retrógrada contínua tépida de baixo volume (8). A solução cardioplégica foi interrompida em intervalos curtos para facilitar a técnica operatória.

O tempo de circulação extracorpórea variou de 31 a 165 min com média e desvio padrão de 76,4 \pm $24,4 \mathrm{~min}$, intervalo de confiança $95 \%$ de $76,4 \pm 5,3$ min e mediana de $72 \mathrm{~min}$. A soma total do tempo de isquemia miocárdica variou de 4 a $36 \mathrm{~min}$, com média e desvio padrão de 16,8 \pm 7,0 min, intervalo de confiança $95 \%$ de $16,8 \pm 1,5 \mathrm{~min}$ e mediana de 15 min. Nos 20 (18,5\%) pacientes operados sem circulação extracorpórea, o tempo despendido para a realização das anastomoses foi, em média, de $15 \mathrm{~min}$.

Foram feitas dosagens de troponina I nos seguintes momentos:

1) pré-operatório;

2) chegada do paciente na UTI;

3) uma vez ao dia, pela manhã, no primeiro e segundo dias de pós-operatório.

O método empregado na dosagem da troponina I foi o da Quimioluminiscência, em equipamento Acess da Sanofi-Pasteur, admitindo-se como normais valores abaixo de 0,1 nanogramas por mililitro $(\mathrm{ng} / \mathrm{ml})$.

Os pacientes foram avaliados pós-operatoriamente, registrando-se a evolução em meses, com vistas à determinação das taxas de sobrevivência. $O$ único evento levado em consideração foi o óbito de causa cardíaca. Foi admitida como sendo de causa cardíaca toda morte não decorrente de complicações neurológica, hemorrágica ou infecciosa primárias e também não decorrente de acidente ou trauma mecânico. 
Leal J C F, Braile D M, Godoy M F, Purini Neto J, Paula Neto A, Ramin S L, Zaiantchick M - Avaliação imediata da troponina I cardíaca em pacientes submetidos à revascularização do miocárdio. $\quad$ Rev Bras Cir Cardiovasc 1999; 14 (3): 247-53.

Para fins de análise dos dados, os pacientes foram divididos em dois grupos: Grupo I, constituído pelos 88 pacientes submetidos à revascularização miocárdica com auxílio de circulação extracorpórea e Grupo II, constituído pelos 20 pacientes submetidos à revascularização sem circulação extracorpórea (via esternotomia mediana ou com minitoracotomia anterior esquerda). Foram realizados os cálculos de média, desvio-padrão e intervalo de confiança 95\% tanto para troponina I sérica quanto para troponina I total. A troponina I total foi calculada multiplicando-se o valor da troponina I sérica pela volemia do paciente, considerando-se a volemia equivalente a $80 \mathrm{ml}$ por quilograma de peso e referida em miligramas.

Para aferição prognóstica dos valores de troponina I sérica, adotaram-se níveis de corte em $0,5 \mathrm{ng} / \mathrm{ml}, 1,0 \mathrm{ng} / \mathrm{ml}, 2,5 \mathrm{ng} / \mathrm{ml}$ e $5,0 \mathrm{ng} / \mathrm{ml}$ e para troponina I total, níveis de corte em $2,5 \mathrm{mg}, 5,0 \mathrm{mg}$, $10 \mathrm{mg}$ e $20 \mathrm{mg}$, calculando-se o risco relativo e o intervalo de confiança $95 \%$ para cada situação. Empregaram-se curvas atuariais (Kaplan-Meier) para estudo da sobrevivência a longo prazo, comparando-se os resultados pelo "Logrank test" e pelo "Hazard Ratio", com intervalo de confiança 95\%. As curvas atuariais foram realizadas com auxílio do programa estatístico Graphpad Prism. Utilizou-se ainda o teste $\mathbf{t}$ não pareado, bicaudal, com correção de Welch sempre que necessário, e para tanto empregou-se o programa Graphpad Instat. Admitiuse erro alfa de $5 \%$, considerando-se significativos os valores de $\mathbf{p}$ inferiores a 0,05 .

\section{RESULTADOS}

Os valores séricos médios de troponina I, com respectivos desvios-padrão, intervalo de confiança 95\% e mediana, em nanogramas por mililitro, para os pacientes do Grupo I, encontram-se na Tabela 1. Os valores séricos médios de troponina I, com respectivos desvios-padrão, intervalo de confiança 95\% e mediana, em nanogramas por mililitro, para os pacientes do Grupo II, encontram-se na Tabela 2.

A análise estatística dos resultados constantes das Tabelas 1 e 2, com auxílio do teste $\mathbf{t}$ bicaudal não-pareado e correção de Welch (quando os Grupos apresentavam desvios-padrão diferentes), mostrou não haver diferença significativa entre os valores de pré-operatório, da troponina I sérica $(p=0,5114)$. Com relação aos valores de chegada na UTI, houve diferença significativa entre o Grupo I e II em termos de troponina I sérica $(p=0,0094)$, com valores mais altos no Grupo I. No primeiro dia de pós-operatório, os valores de $\mathbf{p}$ para troponina I sérica foram de 0,0382, mostrando novamente diferença significativa entre os Grupos I e II, com maiores valores no Grupo I. Com relação porém ao segundo dia de pós-operatório, não houve diferença entre os valores de troponina I sérica nos dois Grupos ( $p=0,3752)$.

A informação sobre a evolução tardia dos pacientes, em termos do evento óbito, permitiu a correlação com os níveis séricos da troponina I da fase pós-operatória aguda, com vistas ao estabelecimento de seu valor prognóstico. Os pacientes do Grupo I puderam ser seguidos por um tempo médio de 9,3 $\pm 6,3 \mathrm{~m}$ (mediana $10 \mathrm{~m}$ ), com variação de 0 a 17

TABELA 1

RESULTADOS DA TROPONINA I SÉRICA MÉDIA, \pm DESVIO PADRÃO, + INTERVALO DE CONFIANCA (IC) 95\% E MEDIANA NO PRÉ-OPERATÓRIO, CHEGADA NA UTI, PRIMEIRO PÓS-OPERATÓRIO (1ㅇO) E SEGUNDO PÓS-OPERATÓRIO (2ㅇO), EM NANOGRAMAS POR MILILITRO, NOS 88 PACIENTES DO GRUPO I (COM CEC)

\begin{tabular}{lcccc}
\hline & PRÉ-OPERATÓRIO & CHEGADA NA UTI & 19 PO & 20 PO \\
\hline Média & 0,050 & 1,002 & 1,150 & 0,679 \\
Desvio Padrão & 0,191 & 3,202 & 2,395 & 0,791 \\
IC 95\% & 0,055 & 0,702 & 0,168 & 0,183 \\
Mediana & 0,020 & 0,413 & 0,546 & 0,394 \\
\hline
\end{tabular}

TABELA 2

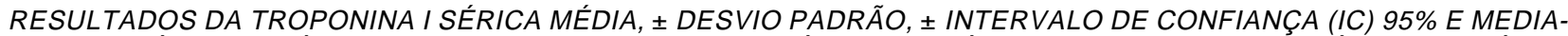
NA NO PRÉ-OPERATÓRIO, CHEGADA NA UTI, PRIMEIRO PÓS-OPERATÓRIO (1ㅇ PO) E SEGUNDO PÓS-OPERATÓRIO (2 PO), EM NANOGRAMAS POR MILILITRO, NOS 20 PACIENTES DO GRUPO II (SEM CEC)

\begin{tabular}{lcccc}
\hline & PRÉ-OPERATÓRIO & CHEGADA NA UTI & 1. PO & 20 PO \\
\hline Média & 0,031 & 0,048 & 0,414 & 0,468 \\
Desvio Padrão & 0,021 & 0,075 & 1,039 & 0,751 \\
IC 95\% & 0,014 & 0,033 & 0,455 & 0,408 \\
Mediana & 0,020 & 0,028 & 0,020 & 0,150 \\
\hline
\end{tabular}


Leal J C F, Braile D M, Godoy M F, Purini Neto J, Paula Neto A, Ramin S L, Zaiantchick M - Avaliação imediata da troponina I cardíaca em pacientes submetidos à revascularização do miocárdio. $\quad$ Rev Bras Cir Cardiovasc 1999; 14 (3): 247-53.

$\mathrm{m}$, enquanto que os pacientes do Grupo II tiveram tempo médio de seguimento de 7,3 \pm 5,4 m (mediana $10 \mathrm{~m}$ ) com variação de 0 a $16 \mathrm{~m}$.

Os cinco óbitos ocorridos no Grupo total perfazem uma mortalidade global de $4,6 \%$ sendo que, no Grupo I, a mortalidade foi de $4,5 \%$ (4/88) e, no Grupo II, foi de 5,0\% (1/20). A Tabela 4 informa sobre o porcentual de mortalidade e a época de ocorrência dos óbitos em relação aos níveis de corte da troponina I sérica. O Gráfico 1 representa a curva atuarial de sobrevivência dos Grupos I e II .

Como um dos objetivos do presente trabalho é investigar o valor prognóstico tardio dos níveis séricos de troponina I, foi construída a curva atuarial de sobrevivência de acordo com os níveis de corte estabelecidos. As correlações foram feitas com os níveis de troponina I do primeiro dia de pós-operatório (PO1) por terem sido estas, em média, as taxas mais altas obtidas. Os Gráficos 2 a 5 representam os achados dessa avaliação, respectivamente para níveis de corte $0,5 \mathrm{ng} / \mathrm{ml}, 1,0 \mathrm{ng} / \mathrm{ml}, 2,5 \mathrm{ng} / \mathrm{ml}$ e $5,0 \mathrm{ng} / \mathrm{ml}$.

Houve, portanto, diferença significativa entre as curvas de sobrevivência a partir do nível de corte de 2,5 $\mathrm{ng} / \mathrm{ml}$ de troponina I sérica.

Quanto ao Risco Relativo de Óbito ao longo da evolução pós-operatória na dependência das faixas de corte para troponina I sérica, os dados encontram-se na Tabela 3.

Observou-se novamente que, com nível de corte em 2,5 ng/ml de troponina I, no primeiro dia de pós-operatório de revascularização miocárdica, foi possível identificar o Grupo de pacientes com risco significativamente maior de falecer em até 17 meses de seguimento.

\section{COMENTÁRIOS}

LÜSCHER et al. (9) (1997) já haviam procurado determinar a aplicabilidade das troponinas $\mathrm{T}$ e I na estratificação de risco de pacientes com doença coronária instável, concluindo que ambas propiciam informação prognóstica independente em relação a morte cardíaca e infarto do miocárdio.

MAIR et al ${ }^{(7)}$. Utilizaram a troponina I para avaliar a ocorrência de infarto miocárdico peri-operatório em pacientes submetidos à revascularização miocárdica com pontes de safena. Esses autores sugerem que, após operações eletivas de revascularização miocárdica, picos de troponina I acima de 3,7 $\mu \mathrm{g} / \mathrm{L}$, concentrações acima de $3,1 \mu \mathrm{g} / \mathrm{L}$ após $12 \mathrm{~h}$ ou concentrações em torno de $2,5 \mu \mathrm{g} / \mathrm{L}$ após $24 \mathrm{~h}$ indicam infarto miocárdico peri-operatório com alta probabilidade.

Os dados que obtivemos são bastante semeIhantes aos da literatura e, na nossa opinião, há evidência suficiente para indicar intervenção precoce (reestudo cineangiográfico, eventual reintervenção cirúrgica ou seguimento ambulatorial intensivo) em pacientes com troponina I sérica no primeiro dia de pós-operatório em níveis acima de $2,5 \mathrm{ng} / \mathrm{ml}$.

GRÁFICO 1

CURVA DE SOBREVIVÊNCIA (KAPLAN-MEIER) PARA O GRUPO I (COM CEC) E PARA O GRUPO II (SEM CEC), ATÉ 17 MESES DE EVOLUÇÃO

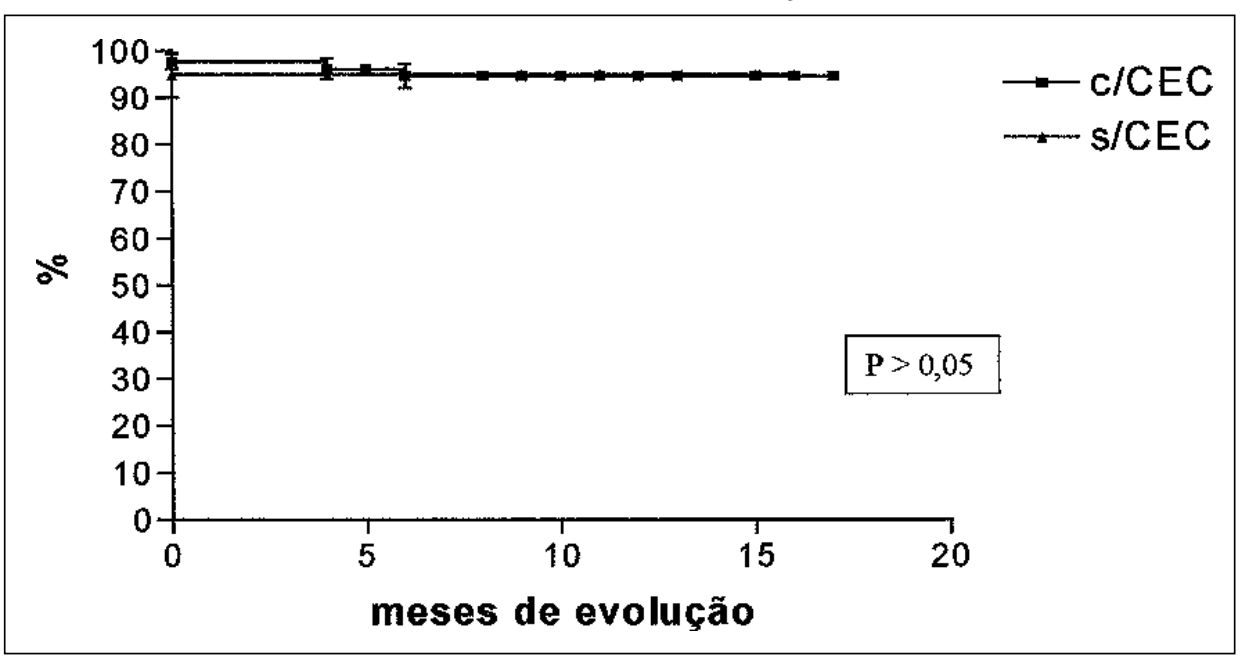

TABELA 3

RISCO RELATIVO DE ÓBITO, EM RELAÇÃO AOS NÍVEIS DE CORTE PARA TROPONINA I SÉRICA (NG/ML) NOS 108 PACIENTES SUBMETIDOS À OPERAÇÃO DE REVASCULARIZAÇÃO MIOCÁRDICA

\begin{tabular}{lccc}
\hline NÍVEL DE CORTE $(\mathbf{n g} / \mathbf{m I})$ & MORTALIDADE $(\%)$ & RISCO RELATIVO & IC 95\% \\
\hline$>0,5$ versus $<0,5$ & $5,9 \times 3,7$ & 1,59 & $0,28-9,12$ \\
$>1,0$ versus $<1,0$ & $12,0 \times 2,5$ & 4,80 & $0,85-27,13$ \\
$>2,5$ versus $<2,5$ & $33,3 \times 3,0$ & 11,00 & $2,25-53,84 *$ \\
$>5,0$ versus $<5,0$ & $50,0 \times 3,9$ & 12,88 & $2,38-69,52 *$ \\
\hline
\end{tabular}

${ }^{*}=p<0,05$ 
GRÁFICO 2

CURVA DE SOBREVIVÊNCIA (KAPLAN-MEIER) PARA O GRUPO TOTAL, ATÉ 17 MESES DE EVOLUÇÃO, COM BASE NA DOSAGEM DE TROPONINA I SÉRICA REALIZADA NO PRIMEIRO DIA DE PÓS-OPERATÓRIO E COM NÍVEL DE CORTE EM 0,5 NG/ML

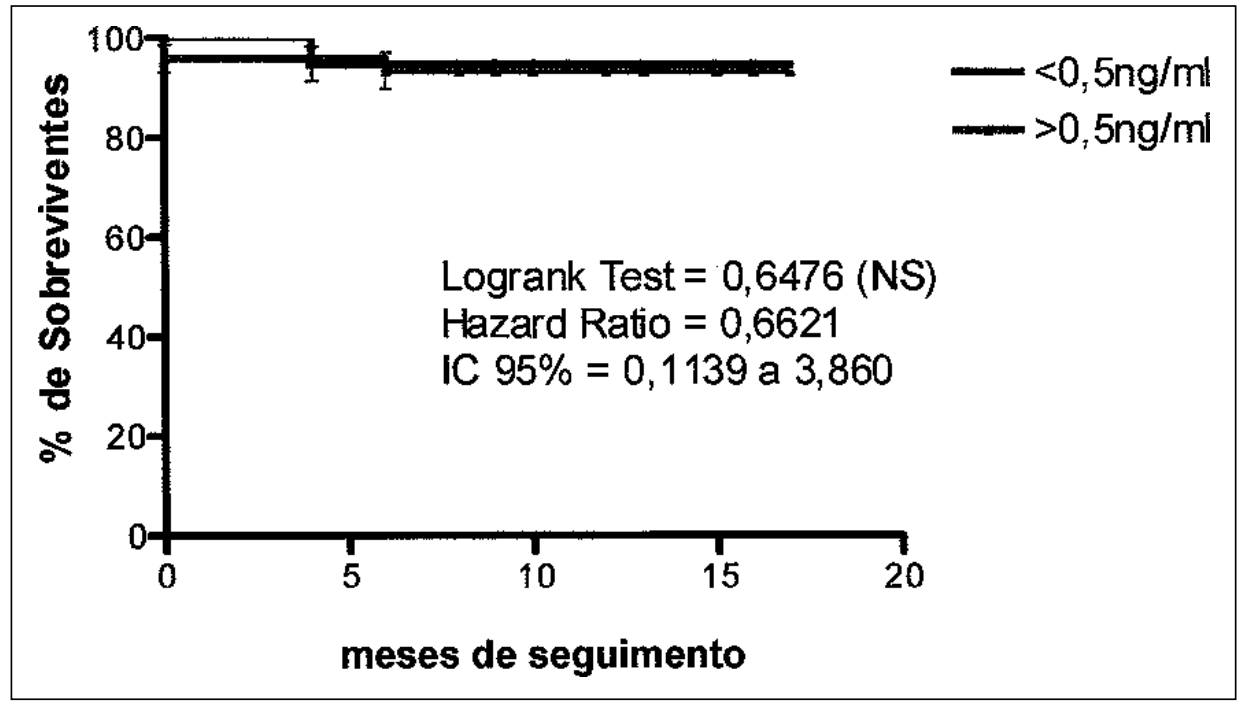

GRÁFICO 3

CURVA DE SOBREVIVÊNCIA (KAPLAN-MEIER) PARA O GRUPO TOTAL, ATÉ 17 MESES DE EVOLUÇÃO, COM BASE NA DOSAGEM DE TROPONINA I SÉRICA REALIZADA NO PRIMEIRO DIA DE PÓSOPERATÓRIO E COM NÍVEL DE CORTE EM 1,0 NG/ML

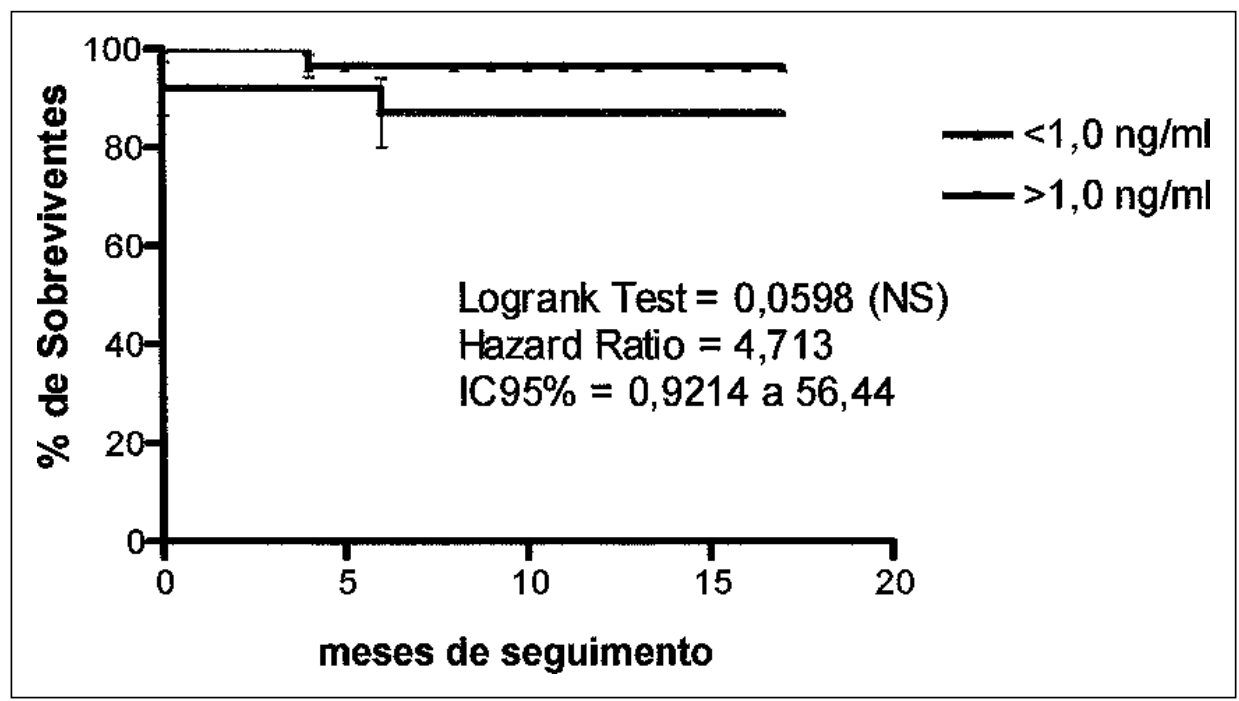

TABELA 4

PORCENTAGEM DE ÓBITOS NO GRUPO TOTAL (GRUPO I + GRUPO II), AO LONGO DO SEGUIMENTO, EM RELAÇÃO À FAIXA DE CORTE NOS NÍVEIS SÉRICOS DE TROPONINA I (NG/ML) NO PRIMEIRO DIA DE PÓS-OPERATÓRIO

FAIXA DE CORTE DA TROPONINA I SÉRICA $(\mathrm{ng} / \mathrm{ml})$

\section{MORTALIDADE AO LONGO} DO SEGUIMENTO (\%)
ÉPOCA DE OCORRÊNCIA DO OBITO

\begin{tabular}{ccc}
\hline Até 0,5 & $3,5 \%$ & 4 meses $/ 4$ meses \\
$>0,5$ & $6,0 \%$ & 8 dias / 8 dias / 6 meses \\
$>1,0$ & $12,0 \%$ & 8 dias / 8 dias / 6 meses \\
$>2,5$ & $33,3 \%$ & 8 dias / 6 meses \\
$>5,0$ & $50,0 \%$ & 6 meses \\
\hline
\end{tabular}


GRÁFICO 4

CURVA DE SOBREVIVÊNCIA (KAPLAN-MEIER) PARA O GRUPO TOTAL, ATÉ 17 MESES DE EVOLUCÃO, COM BASE NA DOSAGEM DE TROPONINA I SÉRICA REALIZADA NO PRIMEIRO DIA DE PÓSOPERATÓRIO E COM NÍVEL DE CORTE EM 2,5 NG/ML

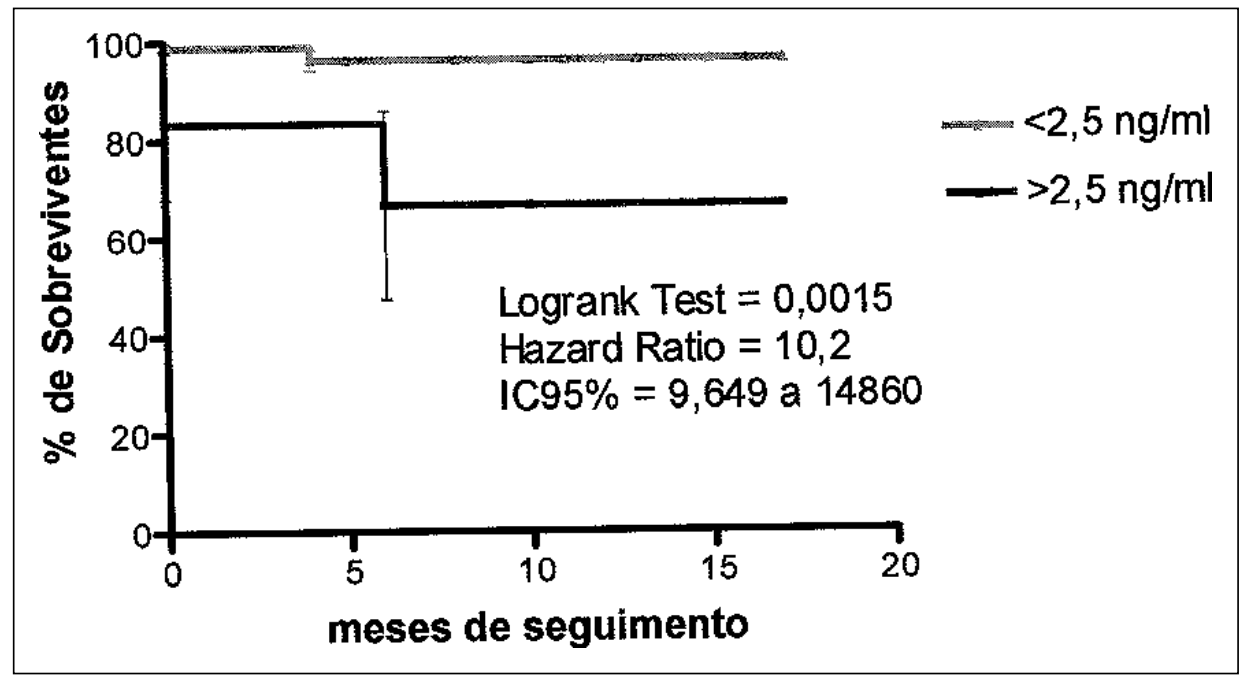

GRÁFICO 5

CURVA DE SOBREVIVÊNCIA (KAPLAN-MEIER) PARA O GRUPO TOTAL, ATÉ 17 MESES DE EVOLUÇÃO, COM BASE NA DOSAGEM DE TROPONINA I SÉRICA REALIZADA NO PRIMEIRO DIA DE PÓSOPERATÓRIO E COM NÍVEL DE CORTE EM 5,0 NG/ML

\begin{tabular}{|l|l|l|}
\hline & & \\
\hline
\end{tabular}

Não foi objetivo do presente trabalho correlacionar os achados de elevação de troponina I com a elevação de enzimas como a CK-MB. As alterações da enzima CK-MB já são bem conhecidas e, além disso, os tempos de elevação e manutenção na circulação dos níveis de CK-MB são bem diferentes dos que ocorrem para a troponina I, o que tornaria a comparação bastante difícil e improdutiva.

O custo da dosagem de troponina I, embora maior que o da dosagem de CK-MB, não é empecilho suficiente, no nosso entender, para que seja utilizado de rotina, uma vez que dispensa a dosagem concomitante de outros marcadores de sofrimento miocárdico e, pelo que demonstramos em nossa casuística, não há necessidade de dosagens freqüentes e seriadas, uma vez que a dosagem do primeiro dia de pós-operatório, isoladamente, já é suficiente para selecionar subgrupos de alto risco.

\section{CONCLUSÕES}

A dosagem de troponina I em pacientes submetidos a operações de revascularização mio- 
Leal J C F, Braile D M, Godoy M F, Purini Neto J, Paula Neto A, Ramin S L, Zaiantchick M - Avaliação imediata da troponina I cardíaca em pacientes submetidos à revascularização do miocárdio. $\quad$ Rev Bras Cir Cardiovasc 1999; 14 (3): 247-53.

cárdica mostrou comportamento evolutivo imediato característico, com importante elevação da concentração sérica já na chegada na UTI e no primeiro dia de pós-operatório. Pacientes operados com auxílio de circulação extracorpórea mostraram níveis significativamente mais elevados, mas não houve correlação com o tempo de isquemia ou tempo de CEC, sugerindo que a elevação da troponina I seja decorrente de sofrimento miocárdico específico (obstrução coronária, oclusão de ponte, etc.) e não da CEC

\author{
propriamente dita ou tempo somatório de \\ isquemia.
}

- Foi possível determinar que os níveis de corte estabelecidos separam pacientes com prognóstico, uma vez que valores acima de $2,5 \mathrm{ng} / \mathrm{ml}$ no primeiro dia de pós-operatório levaram a taxas de mortalidade de $33 \%$ a $50 \%$ nos primeiros seis meses de seguimento. Assim, valores de troponina-l em torno de $2,5 \mathrm{ng} / \mathrm{ml}$ no primeiro dia de pós-operatório devem alertar para a necessidade de medidas diagnósticas ou terapêuticas mais agressivas.

RBCCV 44205-466

Leal J C F, Braile D M, Godoy M F, Purini Neto J, Paula Neto A, Ramin S L, Zaiantchick M - Early evaluation of cardiac troponin I in patients submitted to myocardial revascularization. Rev Bras Cir Cardiovasc 1999; 14 (3): 247-53.

ABSTRACT: The present study was developed to determine the early and late prognosis of patients submitted to myocardial revascularization (with or without extracorporeal circulation) and the relationship with troponin-I serum levels at the postoperative period. One hundred and eight patients were studied between December 1996 and December 1997. The serum troponin-I levels were determined by chemoluminescence (Acess-Sanofi-Pasteur) during four periods: preoperative, admission to Intensive Care Unit, first postoperative day and second postoperative day. Values below $0.1 \mathrm{ng} / \mathrm{ml}$ were considered normal. Cut-off levels for prognostic evaluation $(0.5,1.0,2.5$ and $5.0 \mathrm{ng} / \mathrm{ml})$ were chosen. Follow-up was measured in months with the aim of construction survival curves. The only event considered was cardiac death. Serum troponin-I had a characteristic early behaviour with higher levels on the first postoperative day. When extracorporeal circulation was utilized (Group I), the levels were significantly higher but there was no correlation with ischemic or perfusion times. Perhaps the troponin-I high serum levels could be due to specific myocardial injury, i. e. coronary artery obstruction, saphenous bypass graft acute failure and so on and not due to extracorporeal circulation per se. It was also possible to determine the cut-off levels as markers of poor prognosis. Serum troponin-I higher than 2.5 $\mathrm{ng} / \mathrm{ml}$ on the first postoperative day were followed by mortality rates between $33 \%$ and $50 \%$ up to 6 months of follow-up. Serum troponin-I levels were higher than normal in patients submitted to myocardial revascularization with or without extracorporeal circulation, signifying myocardial cell injury. Values close to $2.5 \mathrm{ng} / \mathrm{ml}$ on the first postoperative day alert to the necessity of more aggressive diagnostic and therapeutic measures.

DESCRIPTORS: Myocardial revascularization, mortality. Troponin I, blood.

\section{REFERÊNCIAS BIBLIOGRÁFICAS}

1 Hamm C W \& Katus H A - New biochemical markers for myocardial cell injury. Curr Opin Cardiol 1995; 10: $355-60$.

2 Mair J-Cardiac troponin I and troponin T: are enzymes still relevant as cardiac markers? Clin Chim Acta 1997; 257: 99-115.

3 Godoy M F, Braile D M, Purini Neto J - A troponina como marcador de injúria celular miocárdica. Arq Bras Cardiol 1998; 71: 629-33.

4 Antman E M, Tanasijevic M J, Thompson B et al - Cardiac specific troponin I levels to predict the risk of mortality in patients with acute coronary syndromes. $N$ Engl $J$ Med 1996; 335: 1342-9.

5 Fonarow G C - UCLA Clinical Practice Guideline:
Cardiac Troponin. I Assay Diagnostic Module, 2(3), 1996 .

6 Mair J, Wagner I, Jakob, G et al. - Different time courses of cardiac contractile proteins after acute myocardial infarction. Clin Chim Acta 1994; 231: 47-60.

7 Mair J, Larue C, Mair P, Balogh D, Calzolari C, Puschendorf B - Use of cardiac troponin I to diagnose perioperative myocardial infarction in coronary artery bypass grafting. Clin Chem 1994; 40: 2066-70.

8 Braile D M - Cardioplegia isotérmica anterógrada retrógrada de baixo volume. Apostila, 1997.

9 Lüscher M S, Thygesen K, Ravkilde J, Heickendorff L - Applicability of cardiac troponin $T$ and I for early risk stratification in unstable coronary artery disease. Circulation 1997; 96: 2578-85. 